\title{
COMUNICAÇÕES
}

\section{Fusarium oxysporum causing wilt in Eustoma grandiflorum in Brazil}

\author{
Ana Carolina Firmino ${ }^{1}$, Fernanda Aparecida Dourado ${ }^{1}$, Edson Luiz Furtado ${ }^{2}$
}

${ }^{1}$ Faculdade de Ciências Agrárias e Tecnológicas, UNESP, Dracena, SP, Brazil. ²Departamento de Produção Vegetal/Defesa Fitossanitária, Faculdade de Ciências Agronômicas, UNESP, Botucatu, SP, Brazil.

Autor para correspondência: Ana Carolina Firmino (anacarfir@gmail.com)

Data de chegada: 29/07/2016. Aceito para publicação em: 10/05/2017.

$10.1590 / 0100-5405 / 167257$

Lisianthus (Eustoma grandiflorum) is currently one of the cut flowers most cultivated in many regions worldwide, as a consequence of its attractive flowers and excellent post-harvest life. Lisianthus plants in the region of Holambra, São Paulo State, Brazil, were found with wilt symptoms and red-brown vascular discoloration. Orange spore masses also formed on the bases. Stem fragments with characteristic symptoms were collected and disinfected by incubation, for one minute, in a solution containing $2 \% \mathrm{NaClO}$; subsequently, the fragments were washed in sterile distilled water and inoculated in a Petri dish containing agar-water medium (10\% agar). Then, they were incubated in BOD (biological oxygen demand) for 3 days at $25^{\circ} \mathrm{C}$, keeping a photoperiod of 12 hours. After germination, mycelia and conidia were transferred to Petri dishes containing potato dextrose agar medium (Difico ${ }^{\circledR}$ ) to allow colonies to grow. Monosporic cultures were established in synthetic nutrient agar (SNA). After seven days, macroconidia with dimensions of $26.43 \times 3.94 \mu \mathrm{m}$ and 3 septs were observed, as well as microconidia with dimensions of $9.03 \times 3.12$ $\mu \mathrm{m}$. Chlamydospores of $7.74 \times 6.63 \mu \mathrm{m}$ were also noted. The ITS 1 and ITS4 region (KX580964) and the $\beta$-tubulin gene (KX580965) sequenced from the isolate showed $99 \%$ similarity to the Fusarium oxysporum isolates from GENBANK-NCBI (KX463005- ITS) and (EF450110 - $\beta$ Tubulin), respectively.

The inoculum was prepared from 2-week old potato dextrose agar medium with $F$. oxysporum cultures. The Petri dishes were flooded with water and conidia; then, they were scraped with an inoculation loop. The conidial suspension was filtered through cheesecloth, quantified and diluted with water. Seedlings were transplanted into the sterilized soil, distributed in $5 \mathrm{~L}$ pots and infested by the addition of $25 \mathrm{~mL}$ of a conidial suspension $\left(10^{6}\right.$ conidia $\mathrm{ml}^{-1}$ ). Plants were inoculated with sterile water as negative control. There were 10 plants per treatment. The inoculated plants were kept in a greenhouse at the average temperature of $27^{\circ} \mathrm{C}$. Wilt symptoms caused by $F$. oxysporum were observed at 30 days after inoculation, and the plant died at 90 days (Figure 1). The fungus was isolated once again in culture medium from the stem of this inoculation, confirming the pathogenicity. This fungus has already been reported causing problems in lisianthus in various parts of the world, such as Italy, Korea, Argentina and the USA. This is the first report of Fusarium oxysporum causing wilt in Eustoma grandiflorum in Brazil.

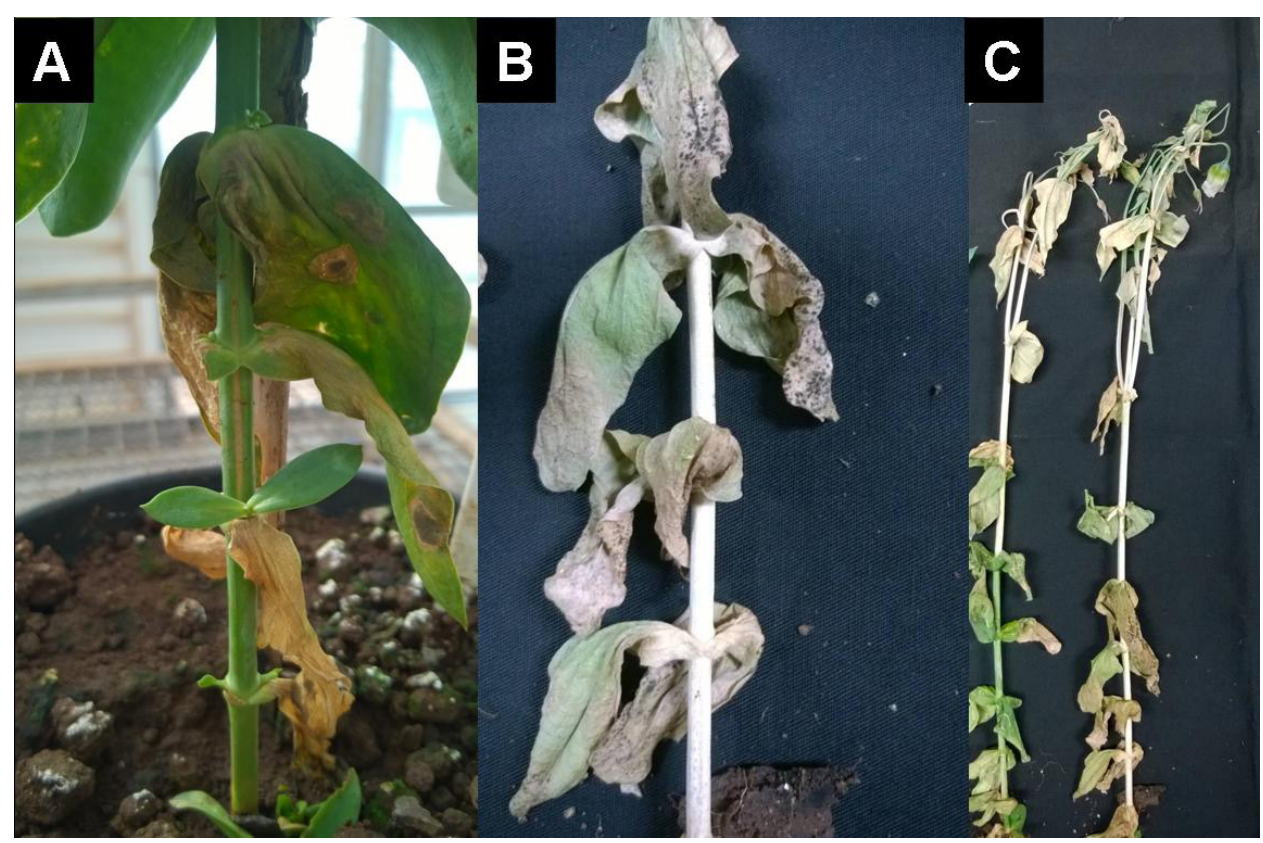

Figure 1. Symptoms caused by Fusarium oxysporum at 30 days after inoculation (A) and at 90 days after inoculation (B and C). 